\title{
LA RESPONSABILIDAD DE LOS PODERES PÚBLICOS: COMENTARIO SOBRE LA SENTENCIA 426/2020 DE 27 DE JULIO DE 2020 (SALA SEGUNDA DEL TRIBUNAL SUPREMO)
}

THE RESPONSIBILITY OF PUBLIC AUTHORITIES: COMMENT ON THE JUDGMENT 426/2020 OF JULY 27, 2020 (SECOND ROOM OF THE SUPREME COURT)

\section{Xosé Antón Sarmiento Méndez}

Universidade de Santiago de Compostela

Cómo citar / Nola aipatu: Sarmiento Méndez, X. A. (2021). La responsabilidad de los poderes públicos: comentario sobre la Sentencia 426/2020 de 27 de julio de 2020 (Sala Segunda del Tribunal Supremo). Legebiltzarreko Aldizkaria - LEGAL - Revista del Parlamento Vasco, 2: 190-199

https://doi.org/10.47984/legal.2021.006

\section{RESUMEN}

El alcance del principio de la interdicción de los poderes públicos es una de las cuestiones esenciales para la comprensión del Estado de derecho. En el caso del ejercicio de la potestad jurisdiccional, la imparcialidad de los tribunales deviene esencial, y la reflexión acerca de su práctica actual resulta de interés para la valoración de la calidad democrática de un sistema político.

\section{PALABRAS CLAVE}

Proceso, imparcialidad, tribunal, derechos fundamentales, Tribunal Europeo de Derechos Humanos, caso Bateragune.

\section{ABSTRACT}

The scope of the principle of the interdiction of public powers is one of the essential issues for understanding the rule of law. In the case of the exercise of jurisdictional power, the impartiality of the courts becomes essential and reflection on their current practice is of interest to assess the democratic quality of a political system.

\section{KEYWORDS}

Process, impartiality, court, fundamental rights, European Court of Human Rights, Bateragune case. 


\section{LABURPENA}

Botere publikoen interdikzioaren printzipioaren norainokoa da zuzenbide-estatua ulertzeko gako garrantzitsuenetako bat. Jurisdikzio-ahalari dagokionez, epaimahaien inpartzialtasuna funtsezko bihurtzen da eta interesgarria da oso haren gaineko egungo praktikari buruz gogoeta egitea sistema politiko baten kalitate demokratikoa balioesteko.

\section{GAKO-HITZAK}

Prozesua, inpartzialtasuna, epaimahaia, funtsezko eskubideak, Giza Eskubideen Europako Auzitegia, Bateragune auzia.

\section{SUMARIO}

I. INTRODUCCIÓN.

II. EL ALCANCE DE LA IMPARCIALIDAD SUBJETIVA DEL JUZGADOR.

III. LA IMPARCIALIDAD JUDICIAL OBJETIVA COMO CRITERIO PREFERENTE.

IV. LA SATISFACCIÓN EQUITATIVA PARA LA PARTE PERJUDICADA. BIBLIOGRAFÍA.

\section{INTRODUCCIÓN}

El asunto objeto del presente comentario, como es conocido, tiene su origen en las demandas $n^{\circ} 4184 / 15,4317 / 15,4323 / 15,5028 / 15$ y 5053/15, interpuestas ante el Tribunal Europeo de Derechos Humanos contra el Reino de España con arreglo al artículo 34 del Convenio para la Protección de los Derechos Humanos y las Libertades Fundamentales por parte de cinco ciudadanos: Sr. Otegi Mondragón, Sra. Jacinto García, Sr. Díez Usabiaga, Sra. Zabaleta Tellería y Sr. Rodríguez Torres.

El 3 de noviembre de 2015 se notificó al Gobierno la queja respecto al derecho a un proceso equitativo ante un tribunal imparcial, garantizado por el artículo $6 \int 1 \mathrm{del}$ convenio, y el resto de demandas (4184/15, 4317/15, 4323/15, 5028/15 y 5053/15) fueron inadmitidas en aplicación del artículo 54 \ 1 del Reglamento del Tribunal. En esa misma fecha, el tribunal decidió acumular las demandas.

No se analizarán los distintos pronunciamientos judiciales que se han dictado por diferentes órganos jurisdiccionales de modo individualizado, sino que se tratará de dar una visión de los principales problemas abordados a nivel judicial español y europeo de la cuestión. Además, debe tenerse en cuenta el contenido constitucional del enfoque adoptado y que, por tanto, no se tratarán aspectos procesales de técnica adjetiva-penal, que exceden el cometido de estas páginas y sobre los que existen excelentes trabajos que se citan en la bibliografía.

1 Para realizar este comentario se ha usado la traducción realizada por el equipo de traducción de la Subdirección General de Constitucional y Derechos Humanos de la Abogacía General del Servicio Jurídico del Estado. Ministerio de Justicia. 
Por otro lado, resulta de gran actualidad, desde otra perspectiva, el problema de la imparcialidad judicial en el ámbito de la Unión Europea. Así, el 7 de abril de 2021, el comisario europeo de Justicia, Didier Reynders, ha manifestado en rueda de prensa que la Ley del Poder Judicial polaca es incompatible con una serie de disposiciones fundamentales de los tratados de la UE. La Comisión Europea considera, además, que la legislación impugnada socava la independencia judicial en Polonia y es incompatible con el Estado de derecho de la Unión. La situación analizada y de máxima actualidad es que la ley recurrida impide que los tribunales polacos apliquen directamente la legislación de la UE para proteger la independencia judicial, incluso mediante procedimientos disciplinarios. También impide que los tribunales polacos soliciten decisiones preliminares sobre tales disposiciones al TJUE. Se manifiesta, y ello está particularmente vinculado con la garantía de la imparcialidad judicial, que los jueces polacos corren el riesgo de ser suspendidos de su cargo y de que se les levante la inmunidad para permitir que se inicien procesos penales contra ellos o para detenerlos.

Como puede observarse, a pesar de ser un fundamento básico de la independencia del poder judicial que está en la esencia del Estado de derecho de las democracias liberales -se ha entendido que el artículo 6 del CEDH es un "sustrato común" de la llamada "Europa de los Derechos"-, el problema de la imparcialidad de los juzgadores dista mucho de ser un problema resuelto en las democracias occidentales, y es una cuestión que también preocupa en ámbitos geográficos distantes, como el americano (así en la Corte IDH, caso Palamara Iribarne v. Chile. Fondo. Reparaciones y Costas. Sentencia de 22 de noviembre de 2005).

\section{EL ALCANCE DE \\ LA IMPARCIALIDAD \\ SUBJETIVA DEL JUZGADOR}

Desde mi punto de vista, hemos de preguntarnos si la garantía de imparcialidad de los tribunales es una cuestión estrictamente procesal o si por el contrario tiene un alcance mayor. La respuesta debe ser terminante: la obligación constitucional de sometimiento a la Constitución y al resto del ordenamiento jurídico contenida en el artículo 9.1 del texto constitucional no admite excepciones y, en este sentido, desde tempranas sentencias el Tribunal Constitucional español se ha pronunciado exigiendo la no transgresión de las normas y, más concretamente, la necesaria actuación conforme a derecho, lo que demanda una actuación conforme a los valores y contenidos básicos del sistema jurídico (STC 53/1985, de 11 de abril, FJ 4).

La doctrina más reputada ha distinguido los conceptos interconectados por la jurisprudencia europea en relación con el par independencia-imparcialidad judicial. De este modo, parece adecuado pensar en la idea constitucional de la independencia ju- 
dicial como un prerrequisito del ejercicio de la potestad jurisdiccional, mientras que la imparcialidad es un carácter básico de la jurisdicción como función propia del titular del órgano judicial.

El TEDH ha afirmado que la imparcialidad, normalmente, supone la ausencia de prejuicio o predeterminación -no debe deducirse un criterio formado con anterioridad sobre el asunto a conocer- y que su existencia o inexistencia se puede analizar desde varias perspectivas. Según el criterio subjetivo, a un tribunal se le debe presumir carente de prejuicios personales o de parcialidad. De este modo, el parámetro del convenio europeo se interpretará en el sentido de que la imparcialidad personal de un juez debe presumirse mientras no se pruebe lo contrario, lo que, a mi juicio, supone una presunción iuris tantum -y así parece entenderse en sentencias como la del caso De Cubber v. Bélgica, de 26 de octubre de 1984, párrafo 25-, que, como se verá, el tribunal no encuentra mucha dificultad para desbaratar en los casos en los que ha existido una muestra de hostilidad o mala voluntad respecto al acusado o incluso razones de orden personal. La prueba que se exige por la jurisprudencia europea se vincula a demostrar que el juez haya mostrado hostilidad -concepto de amplio espectro en la tradición jurídica occidental- o animadversión -lo cual difumina aún más la idea- por razones de carácter personal. En el fondo de esta argumentación está el brocardo de honda tradición británica que dice que "la justicia no solo debe hacerse, sino que debe parecer que se ha hecho", algo que el caso Kress c. Francia, de 7 de junio de 2001, denomina como "teoría de las apariencias" y que se plasma en la posibilidad de dudar legítimamente de la independencia del juzgador.

Por el contrario, nuestro Tribunal Constitucional, en su sentencia de 22 de julio de 2014 , atiende a un criterio de imparcialidad judicial en el que valora la presunta incomunicabilidad de la parcialidad entre diferentes procesos atendiendo a una distinción de las causas suscitadas al respecto -bien es cierto que tal acuerdo se adoptó por un ajustado resultado de votación de siete votos a favor y cinco en contra-.

Lo cierto es que el reconocimiento de la ausencia de una nítida división entre la imparcialidad subjetiva y la objetiva ha llevado a que el tribunal de Estrasburgo se haya centrado en el criterio objetivo.

\author{
III. LA IMPARCIALIDAD \\ JUDICIAL OBJETIVA \\ COMO CRITERIO \\ PREFERENTE
}

La conducta del juzgador es posible que cree dudas objetivas acerca de su carácter imparcial por parte de terceros, pero, además, el criterio objetivo de análisis puede demandar el estudio de convicciones personales. Esta idea nos retrotrae a ciertos procesos de selección de órganos de gobierno y presidencias de colegios judiciales que 
exigen comparecencias previas, al modo de los hearings del derecho anglosajón, donde se testea también el programa judicial de los aspirantes, de modo que los responsables de su designación pueden conocer de primera mano el alcance de las ideas y creencias de los que desempeñarán altas responsabilidades en la creación jurisprudencial del derecho. Por ello, es definitorio tener en cuenta que a la hora de decidir sobre si, a la vista de un enjuiciamiento en particular, hay una razón justificada para temer que un órgano jurisdiccional carece de imparcialidad, el punto de vista de la persona que es objeto del proceso es importante, pero no cabe atribuirle un criterio determinante. El Tribunal Supremo español, en su sentencia de 23 de abril de 1992, afirmó que "un Tribunal deja de ser imparcial cuando realiza acciones que pueden implicar, desde un punto de vista objetivo, una toma de posición respecto de las cuestiones que le son sometidas a su decisión. Por ello la pérdida de imparcialidad depende de las propias acciones de los Jueces".

Lo que a mi modo de ver resulta decisivo es concretizar si el temor a la imparcialidad judicial ha de valorarse como objetivamente justificado, y, para ello, tendremos que analizar los vínculos jerárquicos o de otra naturaleza que existen entre el juez y los otros protagonistas de un procedimiento. Creo que esos vínculos solo tendrán relevancia si son de tal carácter que generan falta de imparcialidad del tribunal y, por lo tanto, no deberán considerarse aquellos de carácter accidental, como la participación ocasional en jornadas de formación para funcionarios o la participación colegiada en órganos de selección en la función pública, y ello tanto para ponderar los vínculos positivos como negativos entre los sujetos a valorar a efectos de apreciar la imparcialidad del juzgador y la confianza que los tribunales deben inspirar en los ciudadanos en una sociedad democrática. Por lo tanto, cualquier juez respecto del cual pueda existir un motivo legítimo para temer su falta de imparcialidad debe abstenerse y, en este sentido, alcanza razonabilidad la afirmación del CGPJ en un reciente comunicado de 5 de marzo de 2021: "La Comisión de Ética Judicial considera poco aconsejable la participación de jueces y magistrados en programas o medios que, por su formato, puedan incitar al debate acalorado, al sensacionalismo o sean identificables por el público en general como alineados ideológicamente con una opción política sesgada y no plural”2.

Se trata, en definitiva, de ciertos hechos verificables que autorizan a sospechar de la imparcialidad del juez (caso Micallef Joseph v. Malta, sentencia de 15 de octubre de 2009) y que, en el caso del Estado español, llevaron a una condena cuando el Tribunal Europeo de Derechos Humanos valoró que los integrantes del tribunal eran profesores asociados de una universidad demandada, lo que se interpretó como clara prueba de los vínculos estrechos, pues habían recibido salarios por tales prestaciones docentes.

2 Nota informativa de la Comisión de Ética Judicial de 5 de marzo de 2021, en relación con el Dictamen (Consulta 06/20) de 24 de febrero de 2021: Principios de independencia, imparcialidad, integridad y corrección: ejercicio de la libertad de expresión por los jueces y las juezas. Recuperado de https://bit.ly/3G9QEuQ 
En el caso que nos ocupa, el temor de falta de imparcialidad se fundaba en el hecho de que la presidenta del tribunal juzgador había sido con anterioridad considerada parcial con relación a uno de los demandantes en el procedimiento penal previo, que no solo se encontraba relacionado con actividades terroristas, sino también con el presunto apoyo a cierta organización ilegal. Obviamente, prima facie no se presenta problema que afecte a una falta de imparcialidad subjetiva por animadversión personal, sino que en la situación creada en el curso de los recursos judiciales presentados hay que analizar la presencia o no de causa de falta de imparcialidad objetiva. Lo cierto es que la pregunta que hizo la presidenta del tribunal y su reacción a la negativa a contestar por parte del afectado aportan datos para valorar, desde una perspectiva objetiva, la existencia de una opinión preformada sobre su culpa. Hay que recordar que la doctrina jurisprudencial española permite al presidente de un tribunal hacer preguntas meramente aclaratorias, pero no sustituir el papel del ministerio fiscal o de la acusación, y menos aún descalificar al acusado con insinuaciones acerca de su defensa que podrían hacernos pensar en una infracción flagrante de la imparcialidad demandada constitucionalmente.

En este orden de cosas, hay que afirmar sin ambages que la libertad de expresión de los miembros de los órganos jurisdiccionales cede en presencia de otros bienes jurídicos, como son los que se relacionan con la efectividad de la tutela judicial efectiva prevista en el artículo 24 de nuestra Constitución. Resulta de interés que el Tribunal Europeo de Derechos Humanos haya puesto de manifiesto con particular matiz el hecho de que el cambio de sentido de la sentencia de los órganos judiciales es indicio de la existencia de falta de imparcialidad del órgano jurisdiccional que condenó al encausado. Coincido en la idea de que una declaración pública de un juez, sea cual sea el foro público en el que se produzca, y con más razón en el curso del ejercicio de su potestad jurisdiccional, lleva a comprometer su imparcialidad cuando de algún modo comunica una valoración previa, tal y como se hizo constar en el caso McGonnell c. Reino Unido, de 8 de febrero de 2000 .

En todo caso, la argumentación del TEDH se sitúa, como él mismo admite, en un contexto muy concreto que, a su juicio, no puede ser obviado, y es la vinculación que ambos procedimientos judiciales tenían en relación con "los actos, valores y/u objetivos de la organización terrorista”. Este criterio de vinculación referido a la organización resulta de utilidad para ese órgano jurisdiccional para justificar los temores relativos a la imparcialidad del tribunal. Opino que se trata de un razonamiento ad hoc, puesto que podrán aparecer supuestos de itinerarios judiciales en los que las causas afecten a sujetos comunes en los que atar una causa de falta de imparcialidad será mucho más difícil y, por tanto, la línea jurisprudencial de interpretación tendrá que romperse.

Un aspecto nuclear de la valoración de la imparcialidad judicial en el caso que nos ocupa es el de que no puede descartarse completamente que la opinión desfavorable de la presidenta del tribunal referida a la culpabilidad del primer demandante pudiera 
haber tenido también un impacto negativo en el resto de los demandantes. Esta idea pone de manifiesto la eficacia expansiva de las garantías de la imparcialidad en la concepción del tribunal europeo puesto que se formula su planteamiento en términos de posible duda razonable. Se trata de un supuesto a diferenciar del conocido en la Sentencia del Tribunal Constitucional 138/1994, de 9 de mayo, en la que se declaró que no existe pérdida de la imparcialidad objetiva cuando el órgano jurisdiccional debe decidir sobre un asunto muy similar a otro ya tratado con anterioridad por él mismo.

A mi modo de ver, la cuestión de la imparcialidad del juzgador debe abordarse también desde una perspectiva del modelo de juez constitucional que requiere el siglo XXI. Se precisa, sin duda, un perfil judicial discreto, que no interviene en asuntos públicos mediante el debate mediático o de redes sociales, pues, de lo contrario, se siembra el campo para posteriores problemas de abstención y recusación en los procedimientos a dilucidar. En este orden de cosas, el tribunal de Estrasburgo ha entendido que no tiene por qué afectar a la imparcialidad del juzgador la existencia de campañas de "ruido mediático", pues es esencial a una sociedad democrática que existan debates públicos sobre cuestiones judicializadas, especialmente cuando estos temas afectan a los titulares de cargos públicos y a aspectos tan destacables como las conexiones entre gobernantes y empresarios (caso Rywin c. Polonia).

Desde la perspectiva del justiciable, un problema de trascendencia es el de determinar su posible deber de denunciar la parcialidad del tribunal o, lo que es más delicado, el de delimitar hasta qué punto existe un deber de conocer las eventuales causas de cuestionamiento de la necesaria imparcialidad. Respecto de esta cuestión, la Sentencia del Tribunal Constitucional 306/2005 desechó el argumento de la notoriedad pública de la condición de magistrado de un tribunal superior de justicia de comunidad autónoma como argumento de reproche al recurrente afectado por la sentencia, al entender que se trata de una presunción de conocimiento que no se apoya en prueba concreta alguna (FJ 2).

Estas ideas resumen el convencimiento de que, en esta materia de la apreciación de parcialidad en el ejercicio de la función jurisdiccional, partiendo -como no puede ser de otra manera- de la redacción legislativa vigente por imperativo claro del mandato constitucional de seguridad jurídica, debe procederse siempre al amparo del criterio de interpretación más favorable a la efectividad de los derechos fundamentales -en este caso, destacadamente, el de tutela judicial efectiva-, pues solo la valoración caso por caso será efectiva para el logro de los objetivos buscados.

IV. LA SATISFACCIÓN EQUITATIVA PARA LA PARTE PERJUDICADA
Con carácter previo, conviene afirmar que la naturaleza subsidiaria del recurso de amparo en el derecho español puede constituirse en casos de valoración de la impar- 
cialidad judicial en una auténtica rémora al contenido esencial de la tutela judicial efectiva del artículo 24 de la Constitución, y esa constatación merece una reflexión lege ferenda respecto a las medidas que son adecuadas para asegurar la vigencia del derecho a un juicio imparcial en al ámbito penal.

Ante una infracción de las garantías de imparcialidad que afectan al contenido del artículo 6 del convenio, la jurisprudencia del Tribunal Europeo de Derechos Humanos se decanta por la solución de reparación consistente en celebrar nuevo juicio o reabrir el caso a solicitud de la persona interesada -existen también casos, como el Piersack $8692 / 79$, en los que se reserva su posición sobre ese punto y postula un hipotético acuerdo entre el estado demandado y el demandante-.

En este sentido, en el derecho español la Ley de Enjuiciamiento Criminal suscita la posibilidad, en su artículo 954.3, de revisar la sentencia aunque sea firme: "Se podrá solicitar la revisión de una resolución judicial firme cuando el Tribunal Europeo de Derechos Humanos haya declarado que dicha resolución fue dictada en violación de alguno de los derechos reconocidos en el Convenio Europeo para la Protección de los Derechos Humanos y Libertades Fundamentales y sus Protocolos, siempre que la violación, por su naturaleza y gravedad, entrañe efectos que persistan y no puedan cesar de ningún otro modo que no sea mediante esta revisión”.

Por este motivo, resulta particularmente criticable que se acuda en estos supuestos al expediente del abono de indemnizaciones, que seguramente el tratado ha pensado para solventar solo los daños que no pueden repararse por otros medios. En este sentido, resulta razonable que el tribunal europeo haya entendido que la constatación de la vulneración es una satisfacción válida en el caso que nos ocupa, y por ello declaró la improcedencia de la reclamación de 40.000 euros por daños morales de uno de los demandantes. Como señala la doctrina "la falta de precisión técnica del concepto 'satisfacción equitativa' ha permitido al Tribunal Europeo de Derechos Humanos no equipararla directamente a una indemnización pecuniaria, pues de hecho no son expresiones sinónimas, a diferencia de lo que sucede con la Convención Americana sobre Derechos Humanos, que sí se refiere expresamente a la concesión de una indemnización económica a favor del perjudicado" (Niño Estébanez, 2019: 43).

Este es un problema relevante, que se suma a la ausencia de un criterio uniforme en la fijación de la satisfacción equitativa ante casos sustancialmente iguales.

El Tribunal Supremo, en su Sentencia 692/2020 -en una línea que, como puede verse, es consolidada en la STS 3612/2020-, aprecia que, desde el punto de vista formal, la anulación de la sentencia de casación exige el dictado de una nueva que resuelva adecuadamente el recurso, de conformidad con la doctrina del TEDH aplicada al caso. Entiende, pues, procedente que, estimado el motivo en el que se alegaba vulneración del derecho a un juez imparcial, procede la nulidad de la sentencia de instancia. De forma coherente a ese principio, el tribunal valora que la anulación de la sentencia supone que las acusaciones, que, en principio, subsisten, no han obtenido una res- 
puesta válida a sus pretensiones. Es un razonamiento admitido por la doctrina, pues debe considerarse que el hecho de que un país asuma el ordenamiento del Consejo de Europa no le obliga a que sus instrumentos internos conlleven una reparación perfecta de los incumplimientos de aquel.

Desde una perspectiva de tutela de los derechos de los justiciables, el Supremo entiende que:

a. "Los acusados han sido privados de libertad en ejecución de una pena impuesta en una sentencia que ha sido declarada nula, y -por ello- tienen derecho a una respuesta en Derecho acerca de la vigencia de su presunción de inocencia respecto de los hechos que les fueron imputados, así como respecto al carácter no delictivo de los mismos".

b. Por otro lado, “... las acusaciones, asistidas del derecho a la tutela judicial efectiva, tienen igualmente derecho a que sus pretensiones, debida y oportunamente formuladas, sean resueltas por una resolución motivada".

En este caso mantuvieron los recurrentes que, de conformidad con la doctrina del TEDH, la reapertura del proceso solo puede acordarse a instancia de los propios acusados. Sin embargo, el Supremo dice que no puede aceptarse su tesis. La estimación de la vulneración de su derecho a juez imparcial, a juicio del Supremo, no puede extender sus efectos a conceder al acusado una disponibilidad sobre el proceso que el derecho interno no le reconoce, dados los bienes jurídicos afectados por el delito del que se le acusaba.

Así, el primer motivo del recurso de casación interpuesto por los recurrentes Casiano y Cecilio se estima, declarando la vulneración de su derecho a un tribunal imparcial, lo que determina la anulación del juicio celebrado en la instancia y la anulación de la sentencia recurrida, acordando la retroacción de las actuaciones al momento anterior al juicio oral, debiendo celebrarse un nuevo juicio contra los acusados que resultaron entonces condenados por un tribunal compuesto por magistrados diferentes de los que dictaron la sentencia que se anula, lo que se presenta como un requisito perfectamente razonable de acuerdo con la consolidada doctrina del TEDH. El principio aplicado en las solicitudes de satisfacción equitativa por el TEDH es el de la restitución in integrum, en la que el demandante debe ser compensado para volver a estar en la situación en la que estaría de no haberse producido tal daño, pero no se precisa en muchas ocasiones qué medida debe adoptarse para proceder a ese fin, lo que ha dado lugar a que la doctrina hable de sentencias "meramente declarativas". Algo semejante en cuanto al daño moral, pues el tribunal realizará una evaluación sobre una base equitativa, lo que me lleva a concluir que será una determinación caso por caso la que se lleve a cabo, sin que quepa apriorísticamente determinar el mandato a adoptar por el órgano constitucional del artículo 123 de la Constitución.

Se trata de un ámbito que, sin duda, puede generar debates futuros, lege ferenda, en relación con la posible aplicación de algoritmos para su resolución en la línea apuntada 
por David Martínez (2019): "El uso de algoritmos, en términos generales, siempre conlleva mejoras de eficiencia, rapidez, previsibilidad y seguridad, dado que se elimina la posibilidad de interferencia de prejuicios o creencias que puedan alterar la aplicación mecánica de las normas". A mi modo de ver, al tratarse de una cuestión que afecta a derechos fundamentales, la utilización de este tipo de técnicas de inteligencia artificial en estos procesos debe introducirse con sumas cautelas de garantías máximas para el justiciable.

En definitiva, hay que afirmar la necesidad de que la garantía de la imparcialidad del juzgador, entendida por nuestro Tribunal Constitucional como un derecho de configuración legal, implica la necesidad de que el legislador de la ley procesal penal respete en su desarrollo el contenido esencial del derecho con el alcance del artículo 53.1 de la Constitución y, para ello, la aplicación de las previsiones legales ha de ser flexible y así lograr una interpretación más adecuada de su esencia.

\section{BIBLIOGRAFÍA}

Martínez Zorrilla, D. (2019). El juez artificial: ¿próxima parada? Oikonomics, 12, 1-12. https://doi. org/10.7238/o.n12.1914

Niño Estébanez, R. (2019). Fuerza obligatoria y ejecución de las sentencias del Tribunal Europeo de
Derechos Humanos en España: el procedimiento de revisión. Valencia: Tirant lo Blanch. Recuperado de http://albergueweb1.uva.es/constitutiva/ wp-content/uploads/2021/02/L09-.pdf 